\title{
The Effect of Anaerobiosis and Uncouplers on the Stimulation of $\beta$-Galactosidase Synthesis by Cyclic 3',5'-Adenosine Monophosphate in Escherichia coli
}

\author{
By M. ABOUD AND M. BURGER \\ Department of Experimental Biology, Weizmann Institute of Science, Rehovot, Israel
}

(Accepted for publication 3 I January 1972)

\begin{abstract}
SUMMARY
Anaerobiosis, dinitrophenol and sodium azide decreased catabolite repression of $\beta$-galactosidase caused by glucose in non-growing Escherichia coli $\mathrm{K}-\mathrm{I} 2$. Anaerobiosis had no effect on the efficiency of exogenous cyclic AMP in stimulating enzyme synthesis. In contrast, dinitrophenol and sodium azide made the synthesis of $\beta$-galactosidase more responsive to exogenous cyclic AMP because the effect of cyclic AMP with dinitrophenol or with sodium azide was markedly greater than the sum of the separate effects of cyclic AMP and of each of the uncouplers. This effect of the uncouplers was unrelated to their action on oxidative phosphorylation because it still occurred under anaerobic conditions. It was also not due to increased accumulation of cyclic AMP by enhanced uptake or by inhibition of cyclic AMPphosphodiesterase.
\end{abstract}

\section{INTRODUCTION}

Cyclic $3^{\prime}, 5^{\prime}$-adenosine monophosphate (cyclic AMP) plays a role in the regulation of the synthesis of $\beta$-galactosidase and some other enzymes. Catabolite repression and transient repression involve depletion of the intracellular cyclic AMP (Makman \& Sutherland, 1965; Perlman \& Pastan, I968; Chambers \& Zubay, 1969; de Crombrugghe, Perlman, Varmus \& Pastan, 1969; Jacquet \& Kepes, 1969). Metabolism of the sugar is not necessary for transient repression (Pastan \& Perlman, 1969; Tyler \& Magasanik, 1970), but the more permanent catabolite repression depends on the efficiency of the catabolism of the sugar and on the consumption of its products by biosynthetic processes. Interference with the sugar catabolism by inhibition of oxidative phosphorylation, or by other means, decreased catabolite repression (Mandelstam, I96I; Dobrogosz, 1965, 1966; Okinaka \& Dobrogosz, 1967), whereas inhibition of anabolic processes did the reverse (Magasanik, I96I; Mandelstam, 196I).

In the present study we explored whether interference with the catabolism of glucose by inhibitors of oxidative phosphorylation, like anaerobiosis and uncouplers, decreased catabolite repression of $\beta$-galactosidase by diminishing the depletion of the intracellular cyclic AMP, or by participation in some other interaction which also affected the synthesis of $\beta$-galactosidase.

\section{METHODS}

Chemicals. The uncouplers used were 2,4-dinitrophenol (DNP) (Eastman Kodak Company, Rochester, New York, U.S.A.) and sodium azide (Nutritional Biochemical Corporation, Cleveland, Ohio, U.S.A.). $\left[{ }^{14} \mathrm{C}\right]$ Alanine (I Io $\mathrm{mCi} / \mathrm{mmol}$ ) was from Schwarz BioResearch, Inc., Orangeburg, New York, U.S.A. All other chemicals were as described by Aboud \& Burger (1970). 


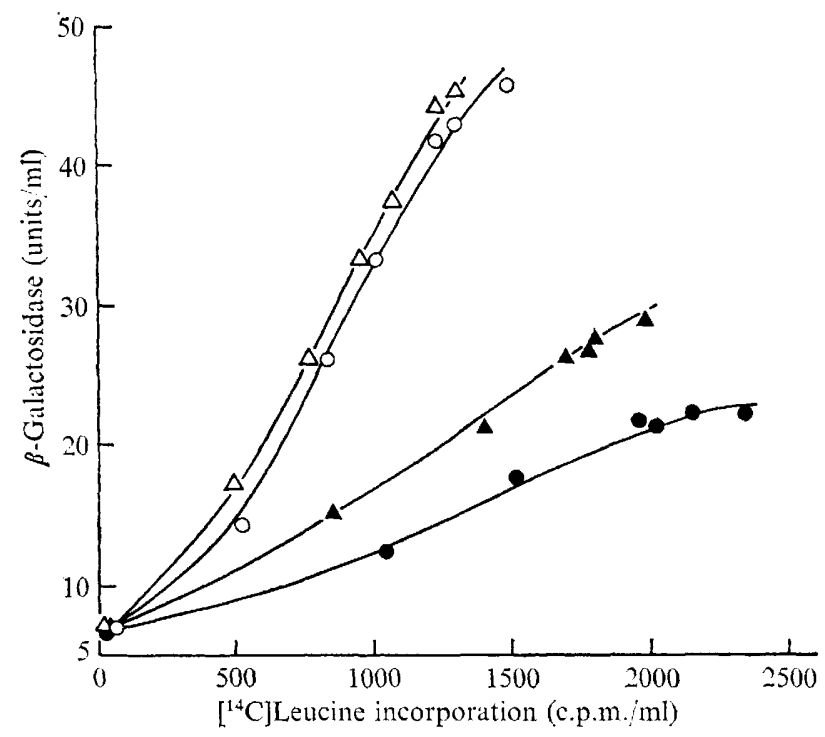

Fig. I. Effect of cyclic AMP and anaerobiosis on $\beta$-galactosidase synthesis. A suspension of bacteria in a nitrogen-deprived medium was divided into four equal portions. Those portions which were to be incubated anaerobically were extensively bubbled with $\mathrm{N}_{2}$ before any addition and while sampling (each $20 \mathrm{~min}$ for assay of $\left[{ }^{14} \mathrm{C}\right]$ leucine incorporation and $\beta$-galactosidase activity). Between samplings the flasks were tightly stoppered. At zero time each portion received IPTG $(0.2 \mathrm{~mm})$, glucose $(0.5 \%$, $\mathrm{w} / \mathrm{v}),\left[{ }^{14} \mathrm{C}\right]$ leucine $(0.05 \mu \mathrm{Ci} / \mathrm{ml})$ and non-radioactive leucine $(10 \mu \mathrm{g} / \mathrm{ml})$ and were incubated under the following conditions: $(\bullet)$, aerobic without cyclic AMP; $(\boldsymbol{\Delta})$, aerobic with ${ }^{\circ} \mathrm{O}$ mM-cyclic AMP; $(O)$, anaerobic without cyclic AMP; $\triangle$ ), anaerobic with I 0 mM-cyclic AMP.

Organisms. Escherichia coli $\mathrm{K}-\mathrm{I} 2 \mathrm{HfrH}$, requiring thiamine, was used throughout most of this study, except for one experiment in which $E$. coli в was used.

Media and growth conditions. Bacteria were subcultured at least once a week on Bacto red bile lactose agar (Difco Laboratories, Detroit, Michigan, U.S.A.). After incubation for about $20 \mathrm{~h}$ at $37^{\circ} \mathrm{C}$ the agar plates were kept in the cold $\left(4^{\circ} \mathrm{C}\right)$ and were used for inoculation of liquid media.

An overnight culture, grown without shaking in a nitrogen-rich medium (Aboud \& Burger, 1970) containing $0.2 \%(\mathrm{w} / \mathrm{v})$ glycerol at $37^{\circ} \mathrm{C}$, was diluted $\mathrm{I}: 100$ in the same medium and incubated with shaking at $37^{\circ} \mathrm{C}$. In one experiment glycerol was replaced by $\mathrm{I} \%(\mathrm{w} / \mathrm{v})$ glucose. At the exponential phase, the bacteria were harvested by centrifuging at $4{ }^{\circ} \mathrm{C}$, washed once with a nitrogen-deprived medium (the nitrogen-rich medium from which all nitrogen sources were omitted), and resuspended in the nitrogen-deprived medium to a density of about $60 \mu \mathrm{g}$ dry wt bacteria $/ \mathrm{ml}$.

Induction and assay of $\beta$-galactosidase. A suspension of washed organisms was induced to synthesize $\beta$-galactosidase by $0.2 \mathrm{~mm}$-isopropyl-thio- $\beta$-D-galactopyranoside (IPTG) in the presence of $0.5 \%$ (w/v) glucose, and assayed as described by Aboud \& Burger (I970).

Incorporation of radioactive amino acids. Total protein synthesis was determined by the incorporation of $\left[{ }^{14} \mathrm{C}\right]$ leucine $(0.05 \mu \mathrm{Ci} / \mathrm{ml})$ added with non-radioactive leucine ( $\left.10 \mu \mathrm{g} / \mathrm{ml}\right)$, except in one experiment when the incorporation of $\left[{ }^{14} \mathrm{C}\right]$ alanine $(0.05 \mu \mathrm{Ci} / \mathrm{ml})$ added with non-radioactive alanine ( $10 \mu \mathrm{g} / \mathrm{ml}$ ) was measured. Incorporation of radioactive amino acids was assayed as described by Aboud \& Burger ( 197 I $a$ ).

Anaerobic conditions. Nitrogen was bubbled through the bacterial suspension before starting the experiment and while sampling; between the samplings the flasks were tightly stoppered. 

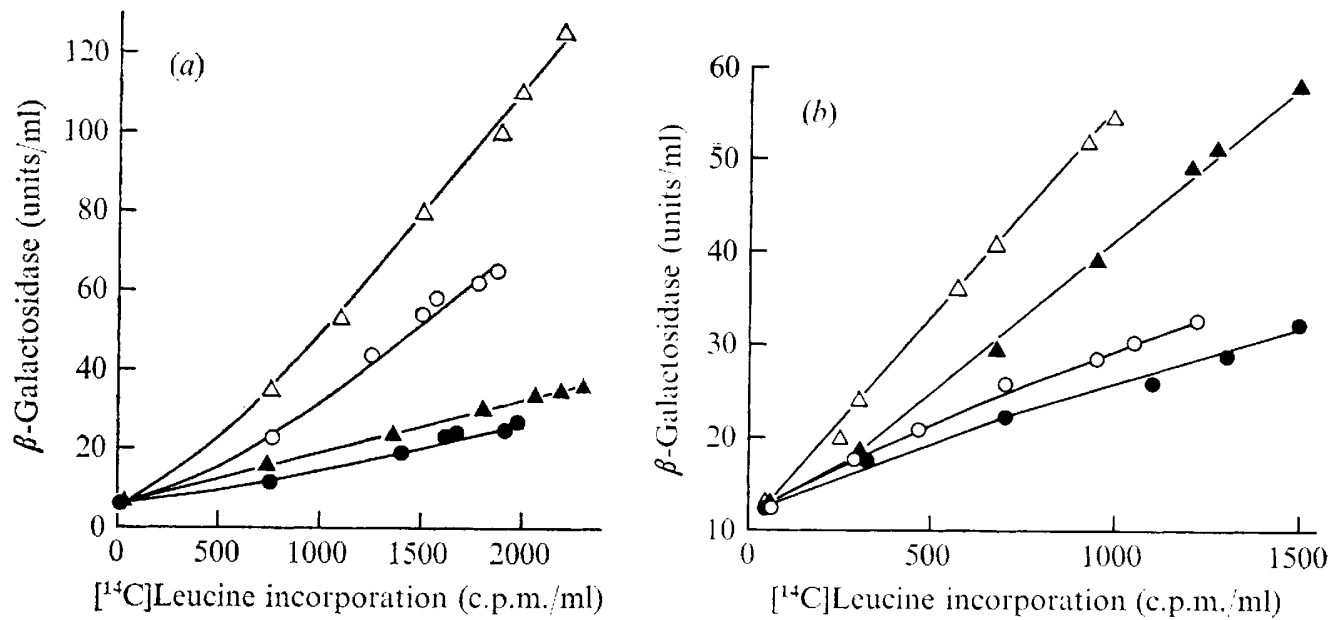

Fig. 2. Effect of cyclic AMP and uncouplers on $\beta$-galactosidase synthesis. A suspension of bacteria in nitrogen-deprived medium received IPTG, glucose, $\left[{ }^{14} \mathrm{C}\right]$ leucine and non-radioactive leucine (as for Fig. I) and was immediately divided into four equal portions which were incubated with: $(a)$

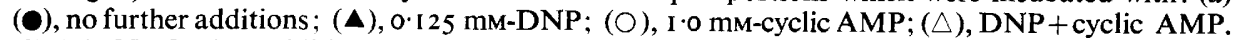

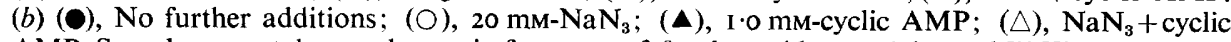
AMP. Samples were taken each $20 \mathrm{~min}$ for assay of $\beta$-galactosidase activity and $\left[{ }^{14} \mathrm{C}\right]$ leucine incorporation.

\section{RESULTS}

Effect of cyclic AMP and anaerobiosis on the differential rate of enzyme synthesis. In none of the experiments was the effect of anaerobiosis and cyclic AMP higher than the sum of their separate effects; in some cases, as in Fig. I, the combined effect was smaller than the sum.

Effect of cyclic AMP and uncouplers. The effect of cyclic AMP with 0.I25 mM-DNP

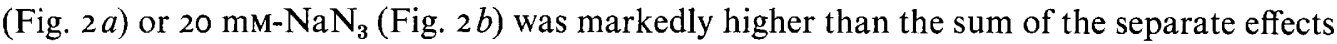
of each. Measurements of $\left[{ }^{14} \mathrm{C}\right]$ alanine incorporation gave similar results with DNP. The stimulatory effect of the uncouplers was therefore not due to a specific inhibition of leucine uptake. None of these uncouplers showed any effect on the activity of $\beta$-galactosidase. Their effect was therefore exerted on the synthesis of the enzyme.

Effect of cyclic AMP with uncouplers under anaerobic conditions. If the effect of the uncouplers in combination with exogenous cyclic AMP was connected with their interference with oxidative phosphorylation, there should be no such effect anaerobically when oxidative phosphorylation was already inactive. Dinitrophenol alone had no significant effect anaerobically, but had a similar effect as under aerobic conditions when cyclic AMP was present (Fig. 3). Similar experiments with $\mathrm{NaN}_{3}$ were unsuccessful, because it inhibited more than $60 \%$ of the $\left[{ }^{14} \mathrm{C}\right]$ leucine incorporation and $\beta$-galactosidase formation at $0.5 \mathrm{~mm}$ while lower concentrations were ineffective.

Effect of DNP in organisms containing a low level of cyclic AMP-phosphodiesterase. Theophylline, an inhibitor of cyclic AMP-phosphodiesterase, increased the stimulation of $\beta$-galactosidase synthesis by exogenous cyclic AMP in bacteria containing a high level of cyclic AMP-phosphodiesterase, such as glycerol-grown Escherichia coli K-I 2 (Aboud \& Burger, I97I $a$ ), but had no effect on cyclic AMP action in organisms lacking cyclic AMPphosphodiesterase, such as $E$. coli $\mathbf{B}$, or having the enzyme only in low levels, such as glucosegrown $E$. coli $\mathrm{K}-\mathrm{I}$ 2. Dinitrophenol also had no effect on $E$. coli $\mathrm{B}$, whether or not exogenous cyclic AMP was present (Fig. 4a). However, unlike theophylline, DNP had some effect on 


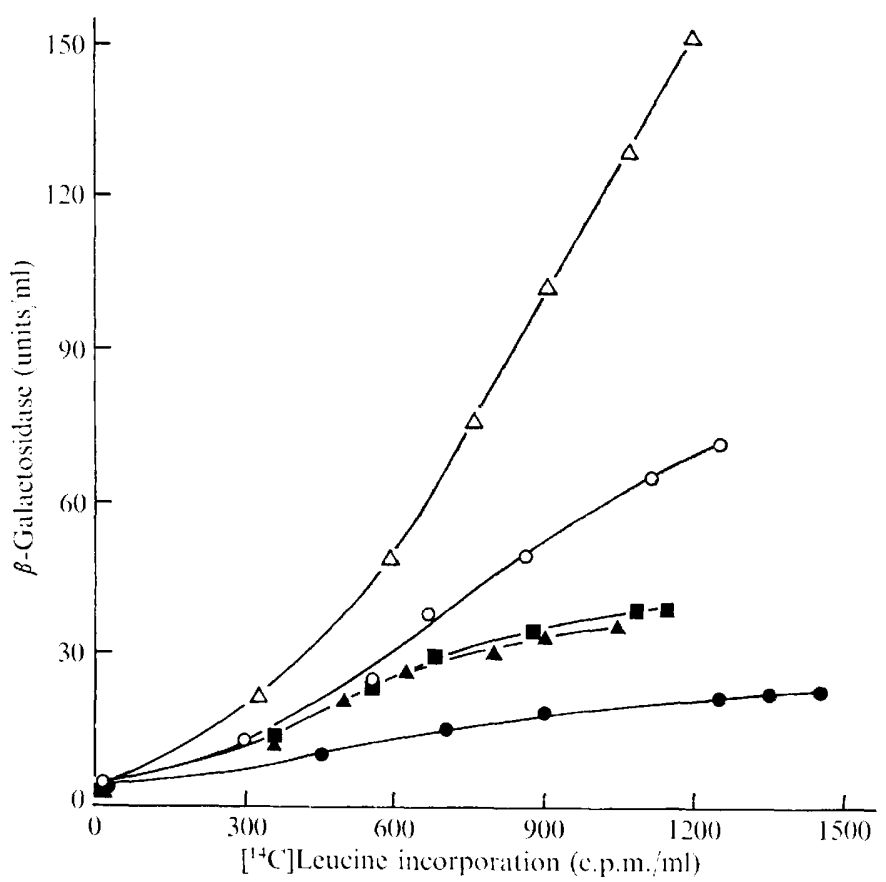

Fig. 3. Effect of cyclic AMP and DNP on $\beta$-galactosidase synthesis under anaerobic conditions. Suspension preparation and anaerobiosis production are described in Fig. I. After receiving IPTG, glucose, $\left[{ }^{14} \mathrm{C}\right]$ leucine and non-radioactive leucine at zero time, each portion of the suspension was incubated under the following conditions: $(\boldsymbol{O})$, aerobic with no further additions; $(\boldsymbol{\Delta})$, anaerobic with no further additions; (घ), anaerobic with $0.125 \mathrm{mM}-\mathrm{DNP} ;(\triangle)$, anaerobic with $0.125 \mathrm{mM}-\mathrm{DNP}$ and I.O mM-cyclic AMP; $(O)$ anaerobic with cyclic AMP. The activity of $\beta$-galactosidase and the incorporation of $\left[{ }^{14} \mathrm{C}\right]$ leucine were assayed in samples taken each $20 \mathrm{~min}$.

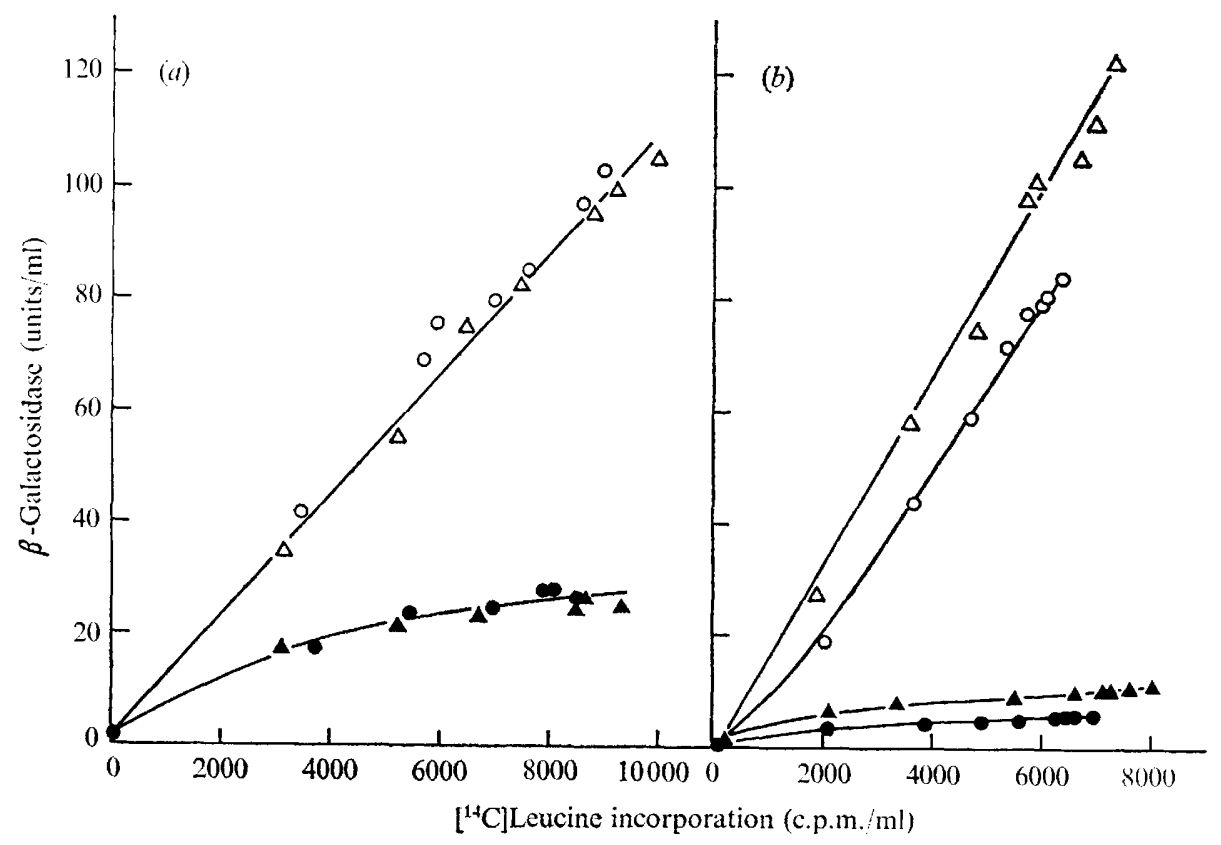

Fig. 4. Effect of cyclic AMP and DNP on $\beta$-galactosidase synthesis in organisms containing low levels of cyclic AMP-phosphodiesterase. The effect of DNP on cyclic AMP action was tested in $(a)$ Escherichia coli B and $(b)$ glucose grown $E$. coli $\mathrm{K}-\mathrm{I} 2$. Other experimental details were as described in Fig. 2 : $(\odot)$, no additions; $(\triangle)$, DNP; $(O)$, cyclic AMP; $(\triangle)$, DNP + cyclic AMP. 


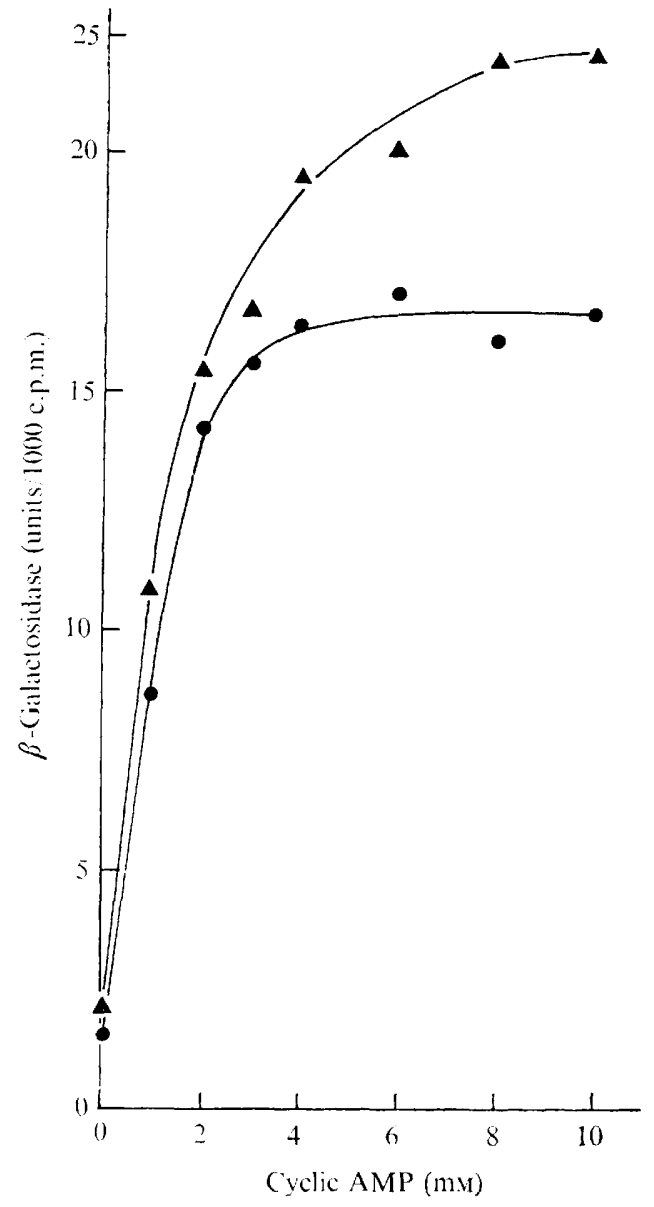

Fig. 5. Effect of various concentrations of cyclic AMP with and without DNP on $\beta$-galactosidase synthesis. A suspension of glycerol-grown Escherichia coli $\mathrm{K}-12$ was divided into several equal portions. Each two portions were subjected to a different concentration of cyclic AMP, one in the presence of $0.125 \mathrm{~mm}$-DNP $(\boldsymbol{\Delta})$ and the other without DNP (-). After $45 \mathrm{~min}$ incubation, samples were taken from all portions for measuring $\beta$-galactosidase activity and $\left[{ }^{14} \mathrm{C}\right]$ leucine incorporation.

the action of cyclic AMP in E. coli $\mathrm{K}-\mathrm{I} 2$ grown with I \% (w/v) glucose instead of glycerol (Fig. $4 b$ ).

Effect of DNP on the relation between $\beta$-galactosidase synthesis and cyclic AMP concentration. The relation between the differential rate of $\beta$-galactosidase synthesis and cyclic AMP concentration was estimated by incubating samples of an induced suspension of organisms with various concentrations of cyclic AMP for $45 \mathrm{~min}$, after which $\beta$-galactosidase formation and $\left[{ }^{14} \mathrm{C}\right]$ leucine incorporation were assayed. There was a linear correlation up to about $2 \mathrm{~mm}$ and a plateau at about $4 \mathrm{~mm}$. With DNP the level of the plateau was higher and it was reached only at a higher concentration of cyclic AMP (Fig. 5).

\section{DISCUSSION}

Catabolite repression of $\beta$-galactosidase, caused by glucose in non-growing Escherichia coli $\mathrm{K}-\mathrm{I} 2$, was decreased by anaerobiosis or less effectively by the uncoupling compounds DNP and $\mathrm{NaN}_{3}$. Uncouplers, in contrast to anaerobiosis, interfere with the active transport 
of $\beta$-galactosides (Pavlasova \& Harold, 1969), and such an interference should result in a lower rate of $\beta$-galactosidase synthesis even if uncouplers release catabolite repression as efficiently as does anaerobiosis.

Since DNP had no significant effect anaerobically on the rate of $\beta$-galactosidase synthesis, when oxidative phosphorylation was already inactive (Fig. 3), the release of catabolite repression by anaerobiosis and the uncouplers must partly result from the inhibition of oxidative phosphorylation.

Catabolite repression is apparently a consequence of depletion of intracellular cyclic AMP (Makman \& Sutherland, I965; Perlman \& Pastan, I968; Chambers \& Zubay, I969; de Crombrugghe et al. 1969; Jacquet \& Kepes, 1969). The inhibitors of oxidative phosphorylation might have released catabolite repression by suppressing the depletion of intracellular cyclic AMP or by some other means. There was a linear correlation between the differential rate of $\beta$-galactosidase formation and the concentrations of cyclic AMP up to $2 \mathrm{mM}$, while higher concentrations caused little further synthesis (Fig. 5). Therefore, if the inhibitors released catabolite repression only by elevating the intracellular cyclic AMP level, the effect of a combination of any of them with I mM-cyclic AMP should be analogous to that of increasing amounts of cyclic AMP, i.e. equal to or lower than the sum of the separate effects of the inhibitors and the exogenous cyclic AMP. The effect of cyclic AMP under anaerobic conditions was indeed equal to the sum of its separate effect plus that of anaerobiosis, or in some cases it was lower. This does not prove that anaerobiosis increased the level of the intracellular cyclic AMP, nor does it exclude this possibility. Inhibition of oxidative phosphorylation by the uncouplers might also raise the intracellular level of cyclic AMP. However, even if this is the case, the uncouplers have some additional effect, not given by anaerobiosis, which makes the synthesis of $\beta$-galactosidase more responsive to exogenous cyclic AMP in their presence than in their absence (Fig. 2, 5). This effect was unrelated to an action on oxidative phosphorylation because, at least in the case of DNP, it occurred also anaerobically (Fig. 3). Other effects of uncouplers, which are not shown by anaerobiosis, have been reported (Galeotti, Kováč \& Hess, I968; Pavlasova \& Harold, I969).

The effect of the uncouplers also could not be due to inhibition of cyclic AMP-phosphodiesterase since DNP increased the effect of exogenous cyclic AMP in glucose-grown Escherichia coli K-1 2 which contained only small amounts of this enzyme (Fig. 4 b). Further, if the effect of the uncouplers was due to inhibition of cyclic AMP-phosphodiesterase or if they increased the accumulation of the exogenous cyclic AMP inside the organisms by enhancing its uptake, then the uncouplers would not affect the level of the plateau in the curve of the relation between the differential rate of $\beta$-galactosidase formation and the concentration of cyclic AMP in the medium, and this plateau would be reached in the presence of the uncouplers with a lower concentration of cyclic AMP. However, with DNP the plateau level was considerably higher and it was reached with a concentration of cyclic AMP almost twice as high as that needed in the absence of DNP (Fig. 5).

It has been reported (Postgate \& Hunter, 1963, I964; Strange \& Dark, 1965; Strange \& Hunter, I966; Calcott \& Postgate, 197I) that carbon sources and some other substrates, which limit the growth rate of certain Gram-negative bacteria, accelerate their death when they are subsequently incubated in non-nutrient buffer. This phenomenon is known as 'substrate-accelerated death'. In most of our experiments glycerol was the limiting substrate during the growth of the bacteria. Such bacteria might, accordingly, be susceptible to glycerolaccelerated death. Both DNP and azide have been shown to protect from glycerol-accelerated death (Postgate \& Hunter, 1964). It could, therefore, be argued that in the presence of the uncouplers there were more viable bacteria which could respond to cyclic AMP, thus 
the stimulation of the differential rate of $\beta$-galactosidase synthesis in such a suspension is higher than in a suspension without uncouplers. However, it should be noted that during the incubation in the nitrogen-deprived medium, in our experiments, glucose replaced glycerol as a carbon source. Contradictory reports as to whether glucose induces substrateaccelerated death in glycerol-limited bacteria have been published (Postgate \& Hunter, 1964; Strange \& Dark, 1965). In an experiment not presented here, we assayed the colonyforming bacteria and after $2 \mathrm{~h}$ incubation we could not detect any significant effect on viability by glucose or by the uncouplers. This could, very possibly, be due to the presence of magnesium ions in the nitrogen deprived-medium, since $\mathrm{Mg}^{2+}$ had been found to prevent substrate-accelerated death (Postgate \& Hunter, I963, I964).

The uncouplers make the synthesis of $\beta$-galactosidase more responsive to exogenous cyclic AMP by a mechanism that is not clear. However, some hypotheses can be suggested.

Unlike transient repression, the permanent catabolite repression depends on the balance between the catabolism of the carbon source and the anabolic pathways. Perhaps catabolite repression depends not only on the level of the intracellular cyclic AMP but also on the accumulation of a metabolite produced during the catabolism of the carbon source, which has a contradictory effect to that of cyclic AMP. The extent of catabolite repression might depend on the ratio between the levels of cyclic AMP and of that metabolite. Our experiments (Aboud \& Burger, I97 $b$ ) strongly suggest that ATP plays such a role in the synthesis of $\beta$-galactosidase and that there is a contradictory relationship between this compound and cyclic AMP. Furthermore, some reports (Galeotti et al. I968; Pavlasova \& Harold, 1969) indicate that uncouplers, in contrast to anaerobiosis, prevent the utilization of ATP in some reactions at the substrate level. By analogy, the uncouplers might similarly prevent the action of ATP in catabolite repression so that cyclic AMP could act without the inhibitory effect of ATP. This hypothesis explains why the synthesis of $\beta$-galactosidase becomes more sensitive to cyclic AMP and responsive to higher concentrations of this nucleotide in the presence of the uncoupler.

Another possible explanation comes from evidence that $\beta$-galactosidase is formed in the cell membrane (Chefurka, Yapo \& Nisman, 1970) and that uncouplers, unlike anaerobiosis, cause changes in the cell membrane (Pavlasova \& Harold, 1969). Changes in the site of $\beta$ galactosidase synthesis may possibly alter the response of this process to cyclic AMP in a way described above.

\section{REFERENCES}

Aboud, M. \& Burger, M. (1970). The effect of catabolite repression and of cyclic $3^{\prime}, 5^{\prime}$ adenosine monophosphate on the translation of the lactose messenger RNA in Escherichia coli. Biochemical and Biophysical Research Communications 38, 1023-1031.

Aboud, M. \& Burger, M. (I971 $a$ ). Cyclic $3^{\prime}, 5^{\prime}$ adenosine monophosphate-phosphodiesterase and the release of catabolite repression of $\beta$-galactosidase by exogenous cyclic $3^{\prime}, 5^{\prime}$ adenosine monophosphate in Escherichia coli. Biochemical and Biophysical Research Communications 43, 174-182.

ABOUD, M. \& BURGER, M. (I97I b). Adenosine triphosphate and catabolite repression of $\beta$-galactosidase in Escherichia coli. Biochemical and Biophysical Research Communications 45, 190-197.

Calcott, P. H. \& Postgate, J. R. (197I). Substrate-accelerated death: Role of recovery medium and prevention by $3^{\prime}, 5^{\prime}$ cyclic AMP. Journal of General Microbiology 66, i.

Chambers, D. A. \& Zubay, G. (I969). The stimulatory effect of cyclic adenosine $3^{\prime}, 5^{\prime}$ monophosphate on DNA directed synthesis of $\beta$-galactosidase in a cell-free system. Proceedings of the National Academy of Sciences of the United States of America 68, $118-122$.

Chefurka, W., YAPO, A. \& Nisman, B. (1970). In vitro synthesis of $\beta$-galactosidase by membrane fractions of E. coli. Canadian Journal of Biochemistry 244, 5828-5835. 
de Crombrugghe, B., Perlman, R. L., Varmus, H. E. \& Pastan, I. (i969). Regulation of inductible enzyme synthesis in Escherichia coli by cyclic adenosine $3^{\prime}, 5^{\prime}$-monophosphate. Journal of Biological Chemistry 244, 5828-5835.

Dobrogosz, W. J. (1965). The influence of nitrate and nitrite reduction on catabolite repression in Escherichia coli. Biochimica et biophysica acta 100, 553-566.

Dobrogosz, W J. ( I966). Altered end-product pattern and catabolite repression in Escherichia coli. Journal of Bacteriology 91, 2263-2269.

GaleotTi, T., Kováč, L. \& Hess, B. (I 968). Interference of uncoupling agents with cellular energy-requiring processes in anaerobic conditions. Nature, London 218, I94-196.

JACQUET, M. \& KEPES, A. (1969). The step sensitive to catabolite repression and its reversal by $3^{\prime}, 5^{\prime}$ cyclic AMP during induced synthesis of $\beta$-galactosidase in E. coli. Biochemical and Biophysical Research Communications 36, 84-92.

Magasanik, B. (1961). Catabolite repression. Cold Spring Harbor Symposia of Quantitative Biology 26, 249-256.

Makman, R. S. \& Sutherland, E. W. (1965). Adenosine 3',5'phosphate in Escherichia coli. Journal of Biological Chemistry 240, I309-I 3 I 3.

MANDELSTAM, J. (I96I). Induction and repression of $\beta$-galactosidase in non-growing Escherichia coli. Biochemical Journal 79, 489-493.

Okinaka, R. T. \& Dobrogosz, W. J. (I967). Catabolite repression and Pasteur effect in Escherichia coli. Archives of Biochemistry and Biophysics 120, 45I-453.

Pastan, I. \& Perlman, R. L. (I969). Repression of $\beta$-galactosidase by glucose in phosphotransferase mutants of Escherichia coli: Repression in the absence of glucose phosphorylation. Journal of Biological Chemistry 244, 5836-5842.

Pavlasova, E. \& Harold, F. M. (1969). Energy coupling in transport of $\beta$-galactosides by Escherichia coli: Effect of proton conductors. Journal of Bacteriology 98, 198-204.

Perlman, R. L. \& Pastan, I. (1968). Cyclic $3^{\prime}, 5^{\prime}$ AMP: Stimulation of $\beta$-galactosidase and tryptophanase induction in E. coli. Biochemical and Biophysical Research Communications 30, 656-664.

Postgate, J. R. \& Hunter, J. R. (I963). Acceleration of bacterial death by growth substrate. Nature, London I98, 273.

Postgate, J. R. \& Hunter, J. R. (I964). Accelerated death of Aerobacter aerogenes starved in the presence of growth-limiting substrates. Journal of General Microbiology 34, 459-473.

Strange, R. E. \& Dark, F. A. (1965). Substrate-accelerated death of Aerobacter aerogenes. Journal of General Microbiology 39, 21 5-228.

Strange, R. E. \& HunTeR, J. R. (I966). Substrate-accelerated death of nitrogen-limited bacteria. Journal of General Microbiology 44, 255-262.

Tyler, B. \& Magasanik, B. (1970). Physiological basis of transient repression of catabolite enzymes in Escherichia coli. Journal of Bacteriology 102, 4I I-422. 